\section{Clinical and diagnostic imaging findings in a bengal tiger (Panthera tigris tigris) with cervical spondylomyelopathy: A case report}

\author{
Achados clínicos e de diagnóstico de imagem em um tigre \\ bengala (Panthera tigris tigris) com espondilomielopatia \\ cervical: Relato de caso
}

\author{
Domenico Fugazzotto ${ }^{*}$, Chiara Costa Devoti ${ }^{2}$, Ilaria Anna Cassano', Chiara Teani ${ }^{2}$, Elisa Berti ${ }^{3}$, Marta Brusati', \\ Offer Zeira ${ }^{4}$ \\ 'Veterinarian, Ospedale Veterinario San Michele, Tavazzano con Villavesco, LO, Italy \\ 2 Veterinarian, MSc, Ospedale Veterinario San Michele, Tavazzano con Villavesco, LO, Italy \\ ${ }^{3}$ Head of Centro Tutela e Ricerca Fauna Esotica e Selvatica Sasso Marconi, (BO), Italy \\ ${ }^{4}$ Veterinarian, PhD, Head of Opsedale Veterinario San Michele, Tavazzano con Villavesco, (LO), Italy
}

\begin{abstract}
An adult neutered male Bengal tiger (Panthera tigris tigris) presented with abnormal gait. Neurological examination showed poor left ambulatory hemiparesis, spontaneous proprioceptive deficit in the left anterior limb, and decreased flexor reflex in the forelimbs. The neurological symptoms suggested a caudal cervical spinal cord lesion. Pathological findings included increased cholinesterase and protein levels in the cerebrospinal fluid. Computed tomography examination revealed C2-C3 intervertebral disc herniation, C5-C6 intervertebral disc herniation associated with a reduction of the intervertebral space, and mild ventral dislocation of the C6 vertebra compared to C5. In addition, severe bilateral shoulder osteoarthritis and a hypoattenuating nodule in the left thyroid gland with an open etiology were observed. These findings were interpreted as indicating cervical spondylomyelopathy (CSM). Treatment included analgesic and steroidal anti-inflammatory therapy as well as movement restriction. Follow-up at 4 weeks showed modest improvement. Thus, CSM should be included in the differential diagnosis of tigers with neurological cervical signs.
\end{abstract}

Keywords: hemiparesis, tetraparesis, feline, wildlife.

\section{Resumo}

Um tigre-de-bengala macho castrado adulto (Panthera tigris tigris) foi apresentado com uma marcha anormal. O exame neurológico mostrou hemiparesia deambulatória deficiente à esquerda, déficit proprioceptivo espontâneo no membro anterior esquerdo e diminuição do reflexo flexor nos membros anteriores. Os sintomas neurológicos sugeriram uma lesão da medula espinhal cervical caudal. Os achados patológicos incluíram aumento do nível de colinesterase e proteínas na bioquímica do LCR. O exame de TC revelou uma hérnia de disco intervertebral C2-C3, uma hérnia de disco intervertebral C5-C6 associada a uma redução do espaço intervertebral e leve deslocamento ventral da vértebra C6 em comparação com C5. Além disso, osteoartrite grave do ombro bilateral e um nódulo hipoatenuante da glândula tireoide esquerda com etiologia aberta. Esses achados foram interpretados como uma espondilomielopatia cervical (CSM). A terapia médica incluiu tratamento analgésico e anti-inflamatório esteroidal, bem como restrição de movimento. O acompanhamento por 4 semanas mostrou uma melhora modesta. A CSM deve ser incluída no diagnóstico diferencial em tigres com sinais neurológicos cervicais.

Palavras-chave: tetraparesia, hemiparesia, felina, selvagem.

\section{Introduction}

Cervical spondylomyelopathy (CSM) is a common cervical spine disease in large and giant breed dogs. It is characterized by dynamic and static compression of the cervical spinal cord and nerve roots, leading to variable grades of neurological signs and neck pain. The pathogenesis of CSM is not fully understood, but is believed to be multifactorial (Da Costa, 2010).
How to cite: Fugazzotto, D., Devoti, C. C., Cassano, I. A., Teani, C., Berti, E., Brusati, M., \& Zeira, O. (2022). Clinical and diagnostic imaging findings in a bengal tiger (Panthera tigris tigris) with cervical spondylomyelopathy: A case report. Brazilian Journal of Veterinary Medicine, 44, e003921. https://doi.org/10.29374/2527-2179.bjvm003921

Received: October 4, 2021 Accepted: January 31, 2022.

\section{*Correspondence}

Domenico Fugazzotto

Ospedale Veterinario San Michele

Via Primo Maggio 37

26838 Tavazzano con Villavesco, (LO), Italy

E-mail: info@ospedalesanmichele.it 
Clinical symptoms vary from isolated pain in the neck to varying degrees of gait disturbances in the hindlimbs, such as ataxia and paraparesis, tetraparesis, or tetraplegia. Compression of the nerve roots, particularly the suprascapular nerve, can cause neurogenic atrophy of the supraspinatus and infraspinatus muscles.

Two different forms of CSM have been well documented in dogs: osseous-associated (OACSM), especially seen in Great Danes and other giant breeds, and disc-associated (DA-CSM), to which Dobermans and other large dogs are predisposed. In OA-CSM, spinal cord and nerve root compression are caused by vertebral canal stenosis secondary to osseous proliferation of the vertebral arch and articular processes (Martin-Vaquero et al., 2014). As a consequence of instability, the surrounding tissues that support cervical articulations tend to proliferate. In Doberman Pinschers, hypertrophy of the interarcuate ligament, dorsal longitudinal ligament, or dorsal annulus may also compress the spinal cord at vertebral articulations.

Canine CSM is comparable to a common neurological disease often diagnosed in older people, termed cervical spondylotic myelopathy or degenerative cervical myelopathy, which is progressive in nature. The natural history of cervical spondylotic myelopathy in people has been documented (Clair \& Bell, 2007; Telekar et al., 2016).

The diagnosis of CSM is commonly made through imaging. Radiographic studies can provide limited information and cannot confirm a diagnosis. Myelography defines the site(s) and direction (ventral, dorsal, or lateral) of spinal cord compression and allows stress or dynamic evaluation of the structures involved (Sharp et al., 1992). Magnetic resonance imaging permits noninvasive evaluation of the spinal cord parenchyma in addition to identification of the lesions (Da Costa et al., 2006; Nye et al., 2020). Computed tomography (CT) myelography has also been used to assess dogs with CSM (Da Costa et al., 2012).

CSM has never been reported in domestic cats, and intervertebral disc herniation is rarely present in feline species and mostly in purebred cats, such as British Shorthairs and Persians (De Decker et al., 2017; Debreuque et al., 2020).

In wild animals, degenerative diseases of the intervertebral disc and congenital diseases of the spine and skull have been described in white lions (Panthera leo krugeri), leopards (Panthera pardus), snow leopard (Panthera uncia), jaguar (Panthera onca), Siberian tiger (Panthera tigris altaica), and zebras (Equus quagga) (Galloway et al., 2002; Kolmstetter et al., 2000; Lambrechts \& Berry, 2000; Montali et al., 1974; Scaglione et al., 2010; Senneca et al., 2018).

CSM has never been described in wild felines, and the objective of this study is to present the first reported case of CSM in a Bengal tiger.

\section{Case report}

A 198-kg 13-year-old captive adult neutered male Bengal tiger (Panthera tigris tigris) was presented with gait abnormality in the left limbs. A physical examination under sedation revealed a good body condition score [3/5]. Neurological examination revealed severe atrophy of the shoulder muscles, poor ambulation, left hemiparesis, spontaneous proprioceptive deficit in the left anterior limb, and decreased flexor reflex in the forelimbs. The cutaneous trunci reflex was normal. Examinations of the cranial nerves and menace responses were normal. A caudal cervical lesion between the C6 and T2 spinal cord segments was suspected. The clinical differential diagnoses included degenerative, neoplastic, or inflammatory disease. The complete blood count and serum biochemistry analysis were normal (Farooq et al., 2012; Liu et al., 2021; Shrivastav \& Singh, 2012)

The Bengal tiger was sedated with dexmedetomidine ( $5 \mu \mathrm{g} / \mathrm{kg}$ i.m.; Dextroquillan, FATRO s.p.a., Ozzano dell'Emilia-BO- 40064, Italy), ketamine (0.7 mg/kg i.m.; Lobotor, ACME srl, 42025, Cavriago -RE-, Italy), and midazolam (0.08 mg/kg i.m.; Midazolam Bioindustria L.I.M., Bioindustria L.I.M., 15067, Novi Ligure -AL-, Italy). General anesthesia was induced with propofol (Proposure, Boehringer Ingelheim Animal Health Italia s.p.a, 20139, Milano, Italy) to achieve orotracheal intubation and maintained with isoflurane (IsoFlo, Zoetis Italia s.r.l., 20124, Milano, Italy) in oxygen with mechanical ventilation. Capnography and halogenates were monitored. The tiger was subjected to continuous ECG, pulse oximetry, and non-invasive blood pressure monitoring.

Arterial blood samples were collected for gas analysis. CT examination of the head and neck region was performed using a 16-slice Siemens Somatom go.Now, which performed multiplanar acquisitions before and after contrast (Omnipaque 300 mg/ml, GE Healthcare, 20126, Milan). CT 
scans showed the presence of a C2-C3 medial disc herniation that was moderately compressive in contact with the spinal cord, which appeared dorsally displaced. At the level of $\mathrm{C} 1$ and $\mathrm{C} 2$, slight hyperattenuation was observed with poorly defined margins of the central portion of the medulla, a reduction of the $\mathrm{C5}$-C6 intervertebral space associated with ventral dislocation of the cranial vertebral endplate of C6 compared to C5, and the presence of C5-C6 disc herniation. There was also a medial and slightly compressive vertebral spondylosis at the C5-C6 and C6-C7 levels, severe bilateral shoulder osteoarthritis characterized by severe periosteal reactivity, subchondral sclerosis, and osteolysis of the proximal humerus and bilateral scapula (Figures 1-3). We also observed bilateral periarticular and synovial effusion as well as a nodular lesion measuring approximately $1.8 \mathrm{~cm} \times 1.2 \mathrm{~cm} \times 1 \mathrm{~cm}$, hypoattenuating both in the basal images and after administration of contrast medium to the left thyroid gland. The right thyroid gland appeared normal.

Urine was collected using a sterile technique and submitted for aerobic/anaerobic culture, which yielded negative results. Physical and chemical urine tests were also performed, the results of which were normal. Cerebrospinal fluid (CSF) was obtained from the cerebellomedullary cistern. CSF cell counts and cytology results were normal, and biochemistry tests showed elevated cholinesterase and protein levels (Martin-Vaquero et al., 2015). CSF PCRs for Neospora caninum, Toxoplasma gondii, canine distemper, FIP, Ehrlichia spp., and Borrelia burgdorferii were performed by the Genefast laboratory (Bazzano-Bologna, 40052, Italy), all of which yielded negative results. The tiger was prescribed prednisolone $(0.5 \mathrm{mg} / \mathrm{kg}$, once daily for 30 days; Prednicortone $20 \mathrm{mg}$, Dechra Veterinary Products S.r.l) and tramadol hydrochloride (2 mg/kg, twice daily for 20 days; Altadol, Formevet s.r.l) along with severe exercise restriction. A follow-up examination 4 weeks after the initial presentation showed moderate improvement in the left ambulatory hemiparesis with spontaneous proprioceptive deficit in the left anterior limb.

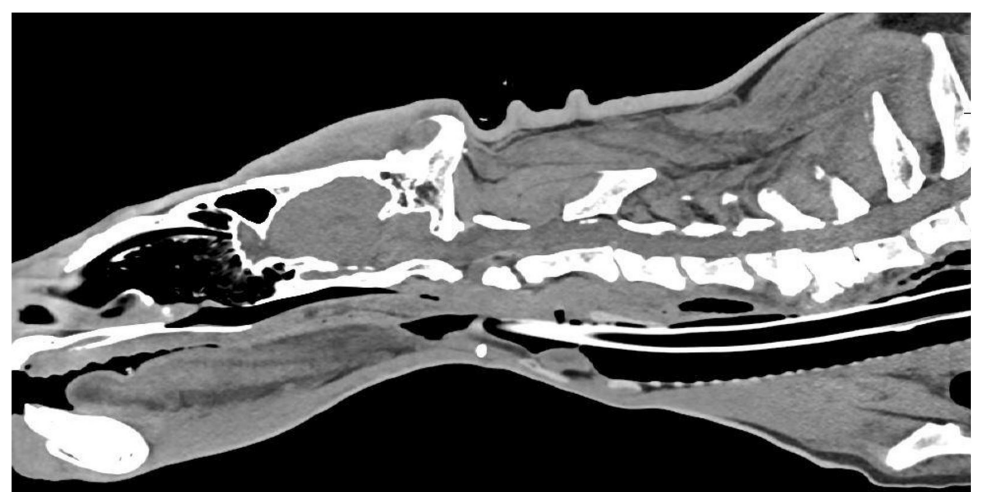

Figure 1. Sagittal CT scan, soft tissue window, of a 13-year-old Bengal tiger affected by cervical spondylomyelopathy. Note the reduction of the C5-C6 intervertebral space, associated with the ventral dislocation of the cranial vertebral end-plate of C6 compared to C5. The presence of medial C5-C6 disc herniation, slightly compressive, and of vertebral spondylosis in C5-C6 and C6-C7 can be observed.

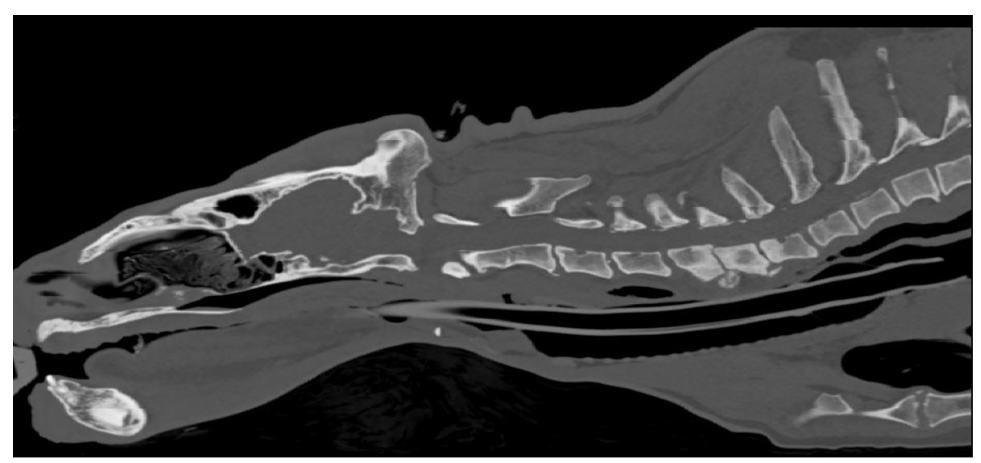

Figure 2. Sagittal CT scan of the bone window: A13-year-old Bengal tiger affected by cervical spondylomyelopathy. Note the reduction of in the C5-C6 intervertebral space, associated with ventral dislocation of the cranial vertebral end-plate of C6 compared to C5. The presence of medial C5-C6 disc herniation, slightly compressive, and of vertebral spondylosis in C5-C6 and C6-C7 can be observed. 


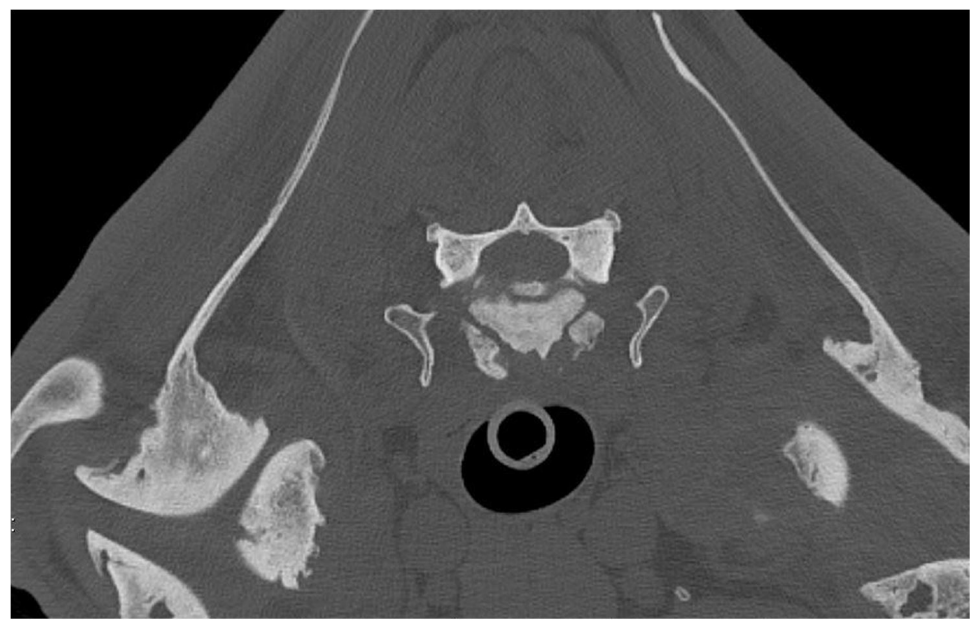

Figure 3.Transverse CT scan of the C5-C6 bone window: A 13-year-old Bengal tiger affected by cervical spondylomyelopathy. Note a reduction inof the C5-C6 intervertebral space. Marginal osteophytes were visualized at the shoulder joint.

\section{Discussion}

CSM treatment can be medical, surgical, or a combination of the two.

The most important part of medical management is exercise reduction to minimize high-impact activities that exacerbate the dynamic component of spinal cord compression. Corticosteroids appear to benefit dogs with CSM, and anti-inflammatory dosages of prednisone are often used ( 0.5 to $1.0 \mathrm{mg} / \mathrm{kg}$ once or twice daily), with the dosage progressively tapered over the course of 2-3 weeks. Despite the potential benefits associated with corticosteroid therapy, the use of corticosteroids, particularly for long periods, is associated with serious adverse effects. NSAIDs can be used in place of corticosteroids if neck pain appears to be the main component of the syndrome or if the adverse effects of corticosteroids cannot be tolerated (Da Costa et al., 2008). The response to medical treatment (corticosteroids and exercise restriction) can also be used to indirectly assess the degree of reversibility of spinal cord injuries (Wheeler \& Sharp, 1994).

Surgical treatment is generally considered to be the treatment of choice for CSM. Various surgical techniques have been used in dogs. Direct decompressive techniques include dorsal laminectomy, dorsal laminoplasty, ventral slot, inverted cone slot, and hemilaminectomy (Chambers et al., 1986; De Risio at al., 2002; Jeffery, 1995). Indirect decompressive techniques include distractionstabilization, fusion cage, and cervical arthroplasty (Adamo, 2011; Da Costa, 2010).

As most affected dogs have spinal cord compression, decompressive spinal cord surgery should lead to a definitive treatment. However, the decision to recommend surgical treatment should be based on several factors, such as the severity of neurologic signs, pain, type and severity of compressive lesion(s), response (or lack thereof) to medical management, and the short- and long-term expectations of the owner. It should be taken into account that the presence of other concurrent neurologic or orthopedic problems or non-neurologic diseases, such as dilated cardiomyopathy, may affect long-term outcomes. The most common complications are progressive deterioration of neurological status, implant failure, and development of a compressive lesion at a neighboring intervertebral space (the domino effect) (Dewey \& Da Costa, 2015; Jaggy \& Platt, 2010).

In the present case, we preferred conservative treatment with prednisolone $(0.5 \mathrm{mg} / \mathrm{kg}$, once daily, for 30 days), tramadol ( $2 \mathrm{mg} / \mathrm{kg}$, twice daily, for 20 days), and cage rest due to the size of the tiger, challenges of possible postoperative management of a wild animal, and lack of literature to support surgical treatment. Follow-up after 4 weeks showed moderate neurological improvements.

The CSM of this tiger showed characteristics that are more similar to those of disc-associated CSM, as it is present in an adult, without evidence of clear vertebral canal stenosis and with the presence of a C5-C6 disc herniation associated with ventral dislocation of the cranial vertebral endplate of C6 compared to C5 (Da Costa, 2010). Indeed, this condition is sometimes observed in combination with mild vertebral abnormalities and dorsal compression resulting from ligamentum 
flavum hypertrophy (De Decker et al., 2012). As this is the first case described in tigers, it is not possible to postulate whether this species can also develop OA-CSM.

\section{Conclusions}

To the best of our knowledge, there are no previous reports of CSM in Bengal tigers, and this disease should be included in the differential diagnosis of spinal cord diseases in this species. The tiger showed moderate improvement with only conservative medical treatment.

\section{Ethics statement}

The study procedures followed the current research ethics guidelines.

\section{Financial support}

None.

\section{Conflict of interests}

The authors declare no conflict of interests concerning the publication of this article.

\section{Authors' contributions}

DF- Writing, Review and Editing manuscript. CT, IC, EB, MB, CCD, OZ - Review and Editing manuscript.

\section{Availability of complementary results}

All procediments were consented by the animal owner (for case reports).

The work was carried out at Ospedale Veterinario San Michele, Tavazzano con Villavesco, Lodi, Italy.

\section{References}

Adamo, P. F. (2011). Cervical arthroplasty in two dogs with disk-associated cervical spondylomyelopathy. Journal of the American Veterinary Medical Association, 239(6), 808-817. http://dx.doi.org/10.2460/javma.239.6.808. PMid:21916764.

Chambers, J. N., Oliver, J. E., \& Bjorling, D. E. (1986). Update on ventral decompression for caudal cervical disk herniation in Doberman-Pinschers. Journal of the American Animal Hospital Association, 22(6), 775-778.

Clair, S. S., Bell, G. R. (2007). Natural history of cervical spondylotic myelopathy. Seminars in Spine Surgery, 19(1), 2-5. https://doi.org/10.1053/i.semss.2007.01.005.

Da Costa, R. C. (2010). Cervical spondylomyelopathy (wobbler syndrome) in dogs. Veterinary Clinics: Small Animal Practice, 40(5), 881-913. http://dx.doi.org/10.1016/j.cvsm.2010.06.003. PMid:20732597.

Da Costa, R. C., Parent, J., Dobson, H., Holmberg, D., \& Partlow, G. (2006). Comparison of magnetic resonance imaging and myelography in 18 Doberman pinscher dogs with cervical spondylomyelopathy. Veterinary Radiology \& Ultrasound, 47(6), 523-531. http://dx.doi.org/10.1111/j.1740-8261.2006.00180.x. PMid:17153059.

Da Costa, R. C., Parent, J. M., Holmberg, D. L., Sinclair, D., \& Monteith, G. (2008). Outcome of medical and surgical treatment in dogs with cervical spondylomyelopathy: 104 cases (1988-2004). Journal of the American Veterinary Medical Association, 233(8), 1284-1290. http://dx.doi.org/10.2460/javma.233.8.1284. PMid:18922055.

Da Costa, R. C., Echandi, R. L., \& Beauchamp, D. (2012). Computed tomography myelographic findings in dogs with cervical spondylomyelopathy. Veterinary Radiology \& Ultrasound, 53(1), 64-70. http://dx.doi.org/10.1111/i.17408261.2011.01869.x. PMid:22093094.

De Decker, S., da Costa, R. C., Volk, H. A., \& Van Ham, L. M. L. (2012). Current insights and controversies in the pathogenesis and diagnosis of disc-associated cervical spondylomyelopathy in dogs. The Veterinary Record, 171(21), 531-537. http://dx.doi.org/10.1136/vr.e7952. PMid:23180710.

De Decker, S., Warner, A. S., \& Volk, H. A. (2017). Prevalence and breed predisposition for thoracolumbar intervertebral disc disease in cats. Journal of Feline Medicine and Surgery, 19(4), 419-423. http://dx.doi. org/10.1177/1098612X16630358. PMid:26868632.

De Risio, L., Muñana, K., Murray, M., Olby, N., Sharp, N. J., \& Cuddon, P. (2002). Dorsal laminectomy for caudal cervical spondylomyelopathy: Postoperative recovery and long-term follow-up in 20 dogs. Veterinary Surgery, 31(5), 418-427. http://dx.doi.org/10.1053/jvet.2002.34673. PMid:12209412. 
Debreuque, M., Valin, I., Prata, D., De Fornel, P., \& Thibaud, J. L. (2020). Case report: intramedullary intervertebral disk extrusion in a cat: Clinical, computed tomographic, high-field magnetic resonance imaging, and outcome findings. Frontiers in Veterinary Science, 7,742. http://dx.doi.org/10.3389/fvets.2020.583892. PMid:33134365.

Dewey, C. W., \& Da Costa, R. C. (2015). Practical guide to canine and feline neurology (3rd ed.) John Wiley \& Sons.

Farooq, U., Sajjad, S., Anwar, M., \& Khan, B. N. (2012). Serum chemistry variables of Bengal tigers (Panthera tigris tigris) kept in various forms of captivity. Pakistan Veterinary Journal, 32(2), 283-285. http://www.pvj.com.pk/ pdf-files/32_2/283-285.pdf

Galloway, D. S., Coke, R. L., Rochat, M. C., Radinsky, M. A., Hoover, J. P., Carpenter, J. W., Hubbard, J. J., \& Ketz-Riley, C. J. (2002). Spinal compression due to atlantal vertebral malformation in two African lions (Panthera leo). Journal of Zoo and Wildlife Medicine, 33(3), 249-255. http://dx.doi.org/10.1638/1042-7260(2002)033[0249:SCD TAV]2.0.CO;2. PMid:12462492.

Jaggy, A., \& Platt, S. R. (2010). Small animal neurology: An illustrated text. Schlütersche Verlagsgesellschaft mbH \& Co. KG

Jeffery, N. D. (1995). Handbook of small animal spinal surgery. WB Saunders.

Kolmstetter, C., Munson, L., \& Ramsay, E. C. (2000). Degenerative spinal disease in large felids. Journal of Zoo and Wildlife Medicine, 31(1), 15-19. http://dx.doi.org/10.1638/1042-7260(2000)031[0015:DSDILF]2.0.CO;2. PMid:10884118.

Lambrechts, N. E., \& Berry, W. L. (2000). Caudal cervical disc protrusion in a Bengal tiger (Panthera tigris tigris). Journal of Zoo and Wildlife Medicine, 31(3), 404-407. http://dx.doi.org/10.1638/1042-7260(2000)031[0404:CCD PIA]2.0.CO;2. PMid:11237151.

Liu, E., Ma, L., You, D., Yang, C., Hu, Y., Xu, H., Liu, D., \& Wang, Y. (2021). Haematological and biochemical parameters of captive siberian tigers (Panthera tigris altaica) from the Heilongjiang Province, China. Veterinary Medicine and Science, 7(3), 1015-1022. http://dx.doi.org/10.1002/vms3.395. PMid:33314784.

Martin-Vaquero, P., da Costa, R. C., Allen, M. J., Moore, S. A., Keirsey, J. K., \& Green, K. B. (2015). Proteomic analysis of cerebrospinal fluid in canine cervical spondylomyelopathy. Spine, 40(9), 601-612. http://dx.doi.org/10.1097/ BRS.0000000000000831. PMid:26030213.

Martin-Vaquero, P., da Costa, R. C., \& Lima, C. G. D. (2014). Cervical spondylomyelopathy in Great Danes: A magnetic resonance imaging morphometric study. Veterinary journal (London, England: 1997), 201(1), 64-71. http://dx.doi.org/10.1016/j.tvjl.2014.04.011. PMid:24888675.

Montali, R. J., Bush, M., Sauer, R. M., Gray, C. W., \& Xanten Jr, W. A. (1974). Spinal ataxia in zebras. Comparison with the wobbler syndrome of horses. Veterinary Pathology, 11(1), 68-78. http://dx.doi.org/10.1177/03009858 7401100108. PMid:4432358.

Nye, C., Hostnik, E., Parker, E., Wittum, T., Jones, S., Moore, S., Cook, L., \& da Costa, R. C. (2020). Long-term clinical and magnetic resonance imaging follow-up of dogs with osseous-associated cervical spondylomyelopathy. Journal of Veterinary Internal Medicine, 34(5), 2012-2020. http://dx.doi.org/10.1111/jvim.15866. PMid:32794615.

Scaglione, F. E., Schröder, C., Degiorgi, G., Zeira, O., \& Bollo, E. (2010). Cranial malformations in related whitelions (Panthera leo krugeri). Veterinary Pathology, 47(6), 1095-1099. http://dx.doi.org/10.1177/0300985810382518. PMid:20826844.

Senneca, C., Garcia, G., Rosenberg, J. F., Heard, D., Porter, E., Olivera, L., \& Farina, L. (2018). Acute noncompressive nucleus pulposus extrusion causing paraplegia in a siberian tiger (Panthera tigris altaica). Journal of Zoo and Wildlife Medicine, 49(1), 189-192. http://dx.doi.org/10.1638/2017-0079R1.1. PMid:29517456.

Sharp, N. I. H., Wheeler, S. J., \& Cofone, M. (1992). Radiological evaluation of 'wobbler'syndrome-caudal cervical spondylomyelopathy. The Journal of Small Animal Practice, 33(10), 491-499. http://dx.doi. org/10.1111/j.1748-5827.1992.tb01032.x.

Shrivastav, A. B., \& Singh, K. P. (2012). Tigers blood: Haematological and biochemical studies. In T. E. Moschandreou (Ed.), Blood cell - An overview of studies in hematology (pp. 229-242). IntechOpen. http://dx.doi.org/10.5772/50360.

Talekar, K., Poplawski, M., Hegde, R., Cox, M., \& Flanders, A. (2016). Imaging of spinal cord injury: Acute cervical spinal cord injury, cervical spondylotic myelopathy, and cord herniation. Seminars in ultrasound, CT, and MR, 37(5), 431-447. http://dx.doi.org/10.1053/j.sult.2016.05.007. PMid:27616315.

Wheeler, S. J., \& Sharp, N. J. (1994). Small animal spinal disorders, diagnosis and surgery. Mosby-Wolfe Publishers. 